\title{
Did you hear about HIV self-testing? HIV self-testing awareness after community-based HIVST distribution in rural Zimbabwe
}

\author{
Anke Rotsaert ${ }^{*} \mathbb{0}$, Euphemia Sibanda ${ }^{2,3}$, Karin Hatzold ${ }^{4}$, Cheryl Johnson ${ }^{5,6}$, Elizabeth Corbett ${ }^{6}$, \\ Melissa Neuman ${ }^{7}$ and Frances Cowan ${ }^{2,3}$
}

\begin{abstract}
Background: Several trials of community-based HIV self-testing (HIVST) provide evidence on the acceptability and feasibility of campaign-style distribution to reach first-time testers, men and adolescents. However, we do not know how many remain unaware of HIVST after distribution campaigns, and who these individuals are. Here we look at factors associated with never having heard of HIVST after community-based campaign-style HIVST distribution in rural Zimbabwe between September 2016 and July 2017.
\end{abstract}

Methods: Analysis of representative population-based trial survey data collected from 7146 individuals following community-based HIVST distribution to households was conducted. Factors associated with having never heard of HIVST were determined using multivariable mixed-effects logistic regression adjusted for clustered design.

Results: Among survey participants, 1308 (18.3\%) self-reported having never heard of HIVST. Individuals who were between 20 and 60 years old $\{20-29$ years: $[\mathrm{aOR}=0.74,95 \% \mathrm{Cl}(0.58-0.95)]$, 30-39 years: $[\mathrm{aOR}=0.56,95 \% \mathrm{Cl}(0.42-$ $0.74)], 40-49$ years: $[\mathrm{aOR}=0.50,95 \% \mathrm{Cl}(0.36-0.68)], 50-59$ years $[\mathrm{aOR}=0.58,95 \% \mathrm{Cl}(0.42-0.82)]\}$, who had attained at least ordinary level education $[\mathrm{aOR}=0.51,95 \% \mathrm{Cl}(0.34-0.76)]$, and who had an HIV test before $[\mathrm{aOR}=0.30,95 \%$ $\mathrm{Cl}(0.25-0.37)$ ] were less likely to have never heard of HIVST compared with individuals who were between 16 and 19 years old, who had a lower educational level and who had never tested for HIV before, respectively. In addition, non-household heads or household head representatives [aOR $=1.21,95 \% \mathrm{Cl}(1.01-1.45)]$ were more likely to report never having heard of HIVST compared to household head and representatives.

Conclusions: Around one fifth of survey participants remain unaware of HIVST even after an intensive communitybased door-to-door HIVST distribution. Of note, those least likely to have heard of self-testing were younger, less educated and less likely to have tested previously. Household heads appear to play an important role in granting or denying access to self-testing to other household members during door-to-door distribution. Differentiated distribution models are needed to ensure access to all.

Trial registration PACTR, PACTR201607001701788. Registered 29 June 2016, https://pactr.samrc.ac.za/ PACTR201607001701788

Keywords: HIV self-testing, Community-based distribution

\footnotetext{
${ }^{*}$ Correspondence: arotsaert@itg.be

${ }^{1}$ Department of Public Health, Institute of Tropical Medicine,

Nationalestraat 155, 2000 Antwerp, Belgium

Full list of author information is available at the end of the article
}

\section{Background}

Globally, $19 \%$ of people living with human immunodeficiency virus (HIV) are undiagnosed [1], with men, young people (i.e., 15-24 years old), rural and key populations 
least likely being aware of their status [2]. Innovations to close the gaps in testing coverage and reach underserved are urgently required [3]. Investing in additional, innovative HIV testing strategies such as HIV self-testing (HIVST), where individuals take their own test and interpret the result, may both increase testing coverage and decrease inequities in access.

In 2015, Unitaid invested in a large-scale implementation project, called the Self-Testing AfRica (STAR) initiative. The focus was on generating extensive experience and evidence to scale up access to HIVST across SubSaharan Africa. Since then, HIVST acceptability, feasibility and scalability has been demonstrated across many delivery models in different Eastern and Southern African countries [4-9] allowing policy makers to select the most appropriate HIVST delivery models for their context to complement their existing national HIV testing strategies [10]. Community-based distribution can occur during campaigns, at events, through mobile outreach or door-to-door [11]. Previous studies have demonstrated the effectiveness of community-led HIVST campaigns, community-based secondary or peer-led distribution in increasing HIV testing in underserved subgroups [12-14]. Community-based door-to-door distribution has been shown to both increase testing coverage among first-time testers, men and adolescents as well as linkage to antiretroviral therapy (ART) [15]. We do not clearly understand who is left out by door-to-door distribution, including what proportion remain unaware of HIVST after distribution campaigns, and who these individuals are. The aim here is to describe those who self-reported having never heard of HIVST despite living in a community receiving intensive door-to-door community-based HIVST distribution to inform future HIVST delivery strategies. This information is essential to optimize coverage of HIVST and to close the gaps in HIV testing.

\section{Methods}

Secondary analysis was undertaken on a subset of the population-based survey data collected as part of a cluster-randomized trial of supply-side financial incentives to increase uptake of HIVST and linkage to posttest services nested within a time-trend analysis of linkage to care. The study has been published elsewhere (PACTR201607001701788) [16].

In brief, trained community-based distributors delivered HIVST kits through door-to-door distribution to all households in 38 rural Zimbabwean communities between September 2016 and July 2017. Distribution was carried out over 19 days (range 19-25 days) per community. Six to eight weeks later, after completion of HIVST distribution, a population-based survey was conducted in four randomly selected National Census Office
Enumeration Areas (EA) per community. Within each EA, Open Data kit was used to randomly select $50 \%$ of the households for survey participation, with the aim of recruiting 200 adults per community. Only household members older than or equal to 16 years old were eligible for survey completion, after written informed consent. The survey questionnaire was self-administered on electronic tablets, using Audio Computer Assisted Self Interview (ACASI) and included socio-demographic details, history of HIV testing and ART uptake; access to, use and results of self-testing; and uptake of any health services including confirmatory testing and ART following kit distribution (Additional file 1).

The outcome of interest for this analysis was "ever having heard of HIVST". The variable was defined from the question "Have you heard about HIV self-testing as a method for testing for HIV?". Guided by the definition for HIV self-testing: "HIV self-testing is a process whereby a person who wants to know his or her HIV status collects a specimen, performs a test, and interprets the test result in private". A binary yes or no response was captured. As the research objective of the analysis is focussing on the study population who never heard of HIVST, the reference category for analysis is those who have ever heard of HIVST.

Based on the questions asked in the population-based survey, the following socio-demographic and socio-economic characteristics were considered for the analysis: age, sex, marital status, highest level of education, able to read newspaper or letter, religion, tribe, occupation, regular salary, perception of general health, having lived in the community for the last 12 months, ever tested for HIV and whether one was a head of the household. A household head was defined as the person who is regarded as the custodian of the family and is deferred to for the important decisions of the household. A household representative is the person in charge of the household when the household head is absent. Common mental disorders were measured using the Shona Symptom Questionnaire (SSQ), an indigenous 14-item measure in the Shona language, developed in Zimbabwe, with a cut-off point of 9/14 [17]. All continuous variables were changed into categorical variables to understand how the outcome was distributed among sub-populations. Categorical variables were constructed based on the answer options provided in the population-based survey.

The analysis was conducted in STATA 15.1 (Stata Corporation, College Station, TX, USA). Descriptive analyses describe the characteristics of the survey participants. Factors associated with never having heard of HIVST were determined using multivariable mixed-effects logistic regression of individual-level data with adjustment for random effects to account for the clustered unit of 
randomisation, i.e., household and community level. To select the final minimum adequate model, a backward stepwise selection reduction was applied using the likelihood-ratio test to assess the goodness of fit of two competing statistical models. All independent variables were included in the model except for 'regular salary' and 'able to read a newspaper or letter. These latter variables were excluded as they are interrelated with the variables 'occupation' and 'highest level of education.

\section{Results}

\section{Characteristics of survey participants}

The population-based survey included 7146 people from 3813 households, with a response rate of $83.4 \%$. Not being at home $(n=1091,12.7 \%)$ was main reason for non-response. Almost three quarters of the households $(\mathrm{n}=2769,72.6 \%)$ received an HIVST kit during the distribution campaign. The sample included 2767 men (38.7\%) and 4379 women $(61.3 \%)$. About $42 \%(n=3001)$ of the participants were between 20 and 39 years old. Almost $60 \%(\mathrm{n}=4240)$ were married. The predominant religion was Apostolic $(34.3 \%, \mathrm{n}=2450)$. Most participants were Shona $(69.3 \%, n=4949)$. About $46 \%$ of the participants $(\mathrm{n}=3333)$ were not a household head or a household head representative. Almost half of the survey population $(43.3 \%, \mathrm{n}=3092)$ had no education or only primary education. Being a subsistence farmer $(64.7 \%, \mathrm{n}=4620)$ was the main occupation with $16.1 \%(\mathrm{n}=1153)$ earning a regular salary. More than half of the participants perceived their general health to be very good $(25.9 \%, \mathrm{n}=1852)$ or $\operatorname{good}(37.9 \%, \mathrm{n}=2713)$ and $45.1 \%(\mathrm{n}=3221)$ of the participants had a SSQ score above 9 points suggesting they were at risk of common mental disorders. Although 6335 participants $(88.7 \%)$ reported ever having tested for HIV in the past, $18.3 \%(n=1308)$ self-reported that they had never having heard of HIVST.

\section{Factors associated with never having heard of HIVST}

The multivariable mixed-effects analysis shows that participants between 20 and 60 years old are less likely to have never heard of HIVST $\{20-29$ years: $[\mathrm{aOR}=0.74$, 95\% CI $(0.58-0.95)], 30-39$ years: $[\mathrm{aOR}=0.56,95 \% \mathrm{CI}$ $(0.42-0.74)], 40-49$ years: $[\mathrm{aOR}=0.50,95 \% \mathrm{CI}(0.36-$ $0.68)], 50-59$ years $[\mathrm{aOR}=0.58,95 \% \mathrm{CI}(0.42-0.82)]\}$ compared to participants between 16 and 19 years old (Table 1). Individuals who have been living in the area for the last 12 months $[\mathrm{aOR}=0.48,95 \% \mathrm{CI}(0.36-0.63)]$, who had an HIV test before [aOR $=0.30,95 \%$ CI $(0.25-0.37)]$ and who have attained at least ordinary level education $[\mathrm{aOR}=0.51,95 \% \mathrm{CI}(0.34-0.76)]$ are less likely to have never heard of HIVST than individuals who had not lived in the area over the last 12 months, who had never tested for HIV before and who have a lower educational level.
Non-Shona people, except for the Tonga people, had a statistically significant increased odds of not having heard about HIVST compared to Shona people Ndebele: $[\mathrm{aOR}=1.28,95 \% \mathrm{CI}(1.02-1.61)]$, Kalanga: $[\mathrm{aOR}=1.58$, 95\% CI (1.21-2.07)], Other: [aOR $=1.47,95 \%$ CI $(1.04-$ 2.07)]. Individuals who perceive their health to be poor $[\mathrm{aOR}=1.30,95 \% \mathrm{CI}(1.01-1.67)]$, or who did not answer the general health perception question $[\mathrm{aOR}=2.15$, 95\% CI (1.27-3.65)] have increased odds of never having heard of HIVST compared with those who perceive their general health to be good. Individuals who are not household heads or household head representatives have increased odds of never having heard of HIVST compared to household heads or household head representatives $[\mathrm{aOR}=1.21,95 \% \mathrm{CI}(1.01-1.45)]$.

No significant association was found between having never heard of HIVST among individuals with a formal employment compared to those in other employment categories $[\mathrm{aOR}=1.1795 \% \mathrm{CI}(0.81-1.70)]$.

\section{Discussion}

This study provides insight into factors associated with never having heard of HIVST after intensive community-based campaign-style HIVST distribution in rural Zimbabwe. Among survey participants, nearly one fifth self-reported having never heard of HIVST. Individuals who were between 16 and 19 years old, who had no formal education or had only attended primary school and who had never tested before for HIV were more likely to have never heard of HIVST. In addition, those who were not household heads or household head representatives were more likely to have never heard of HIVST.

Understanding who is missed by door-to-door community-based test distribution will be helpful for designing future HIVST distribution models [18]. Zimbabwe was an early adopter of HIVST. At a time when small HIVST pilot studies were being implemented [19], the Zimbabwean 2015-2016 Demographic and Health Survey (DHS) data showed a population-level awareness for HIVST of only $14.5 \%$ [20]. Comparing this low percentage with the $81.7 \%$ found in this study, shows the positive impact of large-scale implementation studies, such as the STAR Initiative on awareness. As there is a constant evolution in exposure and presence of HIVST overtime, it remains important to examine awareness trends in future national surveys such as DHS.

Similar conclusions in terms of those aware of HIVST were found in the 2015-2016 DHS. Awareness was lower among respondents who were younger (below 20 years) and with lower levels of education (primary education or less) [20]. This is in line with other studies which found that HIV testing and knowledge of HIV status increases with age and educational level [21-23]. 
Table 1 Results multivariable mixed effect logistic regression adjusted for clustering on household and community level

\begin{tabular}{|c|c|c|c|c|c|c|c|c|}
\hline Individual characteristics & $\begin{array}{l}\text { Ever heard of HIVST } \\
\mathbf{N}=5838(\text { Row \%) }\end{array}$ & $\begin{array}{l}\text { Never heard of } \\
\text { HIVST N=1308 (Row } \\
\% \text { ) }\end{array}$ & $O R^{*}$ & $95 \% \mathrm{Cl}$ & P-value & $\mathrm{aOR}^{\$}$ & $95 \% \mathrm{Cl}$ & P-value \\
\hline \multicolumn{9}{|l|}{ Age in groups } \\
\hline 16-19 years & $820(74.3 \%)$ & $284(25.7 \%)$ & - & - & $<0.001$ & - & - & $<0.001$ \\
\hline 20-29 years & $1300(82.4 \%)$ & $277(17.6 \%)$ & 0.57 & $0.46-0.71$ & & 0.74 & $0.58-0.95$ & \\
\hline $30-39$ years & 1239 (87.0\%) & $185(13.0 \%)$ & 0.38 & $0.30-0.49$ & & 0.56 & $0.42-0.74$ & \\
\hline $40-49$ years & $929(87.6 \%)$ & $131(12.4 \%)$ & 0.35 & $0.27-0.45$ & & 0.50 & $0.36-0.68$ & \\
\hline $50-59$ years & $662(84.0 \%)$ & $126(16.0 \%)$ & 0.49 & $0.37-0.64$ & & 0.58 & $0.42-0.82$ & \\
\hline 60 years and older & $867(75.1 \%)$ & $288(24.9 \%)$ & 0.94 & $0.75-1.17$ & & 0.99 & $0.72-1.36$ & \\
\hline Constant & - & - & 0.27 & $0.21-0.34$ & $<0.001$ & - & - & - \\
\hline \multicolumn{9}{|l|}{ Sex } \\
\hline Male & 2213 (79.9\%) & $554(20.1 \%)$ & - & - & $<0.001$ & - & - & - \\
\hline Female & $3625(82.8 \%)$ & $754(17.2 \%)$ & 0.80 & $0.70-0.92$ & & - & - & - \\
\hline Constant & - & - & 0.18 & $0.15-0.22$ & $<0.001$ & - & - & - \\
\hline \multicolumn{9}{|l|}{ Marital status } \\
\hline Married & $3585(84.6 \%)$ & $655(15.4 \%)$ & - & - & $<0.001$ & - & - & - \\
\hline Never married & $1227(75.9 \%)$ & $390(24.1 \%)$ & 1.92 & $1.63-2.27$ & & - & - & - \\
\hline Widowed/separated/divorced & $1026(79.6 \%)$ & $263(20.4 \%)$ & 1.50 & $1.24-1.82$ & & - & - & - \\
\hline Constant & - & - & 0.12 & $0.10-0.15$ & $<0.001$ & - & - & - \\
\hline \multicolumn{9}{|l|}{ Highest level of education } \\
\hline None/primary & $2412(78.1 \%)$ & $680(21.9 \%)$ & - & - & $<0.001$ & - & - & $<0.001$ \\
\hline Some secondary & $1556(81.4 \%)$ & $355(18.6 \%)$ & 0.82 & $0.69-0.96$ & & 0.84 & $0.70-1.02$ & \\
\hline O levels complete ${ }^{\mu}$ & $1571(87.4 \%)$ & $227(12.6 \%)$ & 0.50 & $0.42-0.61$ & & 0.58 & $0.46-0.72$ & \\
\hline A levels and above $e^{£}$ & $299(86.7 \%)$ & $46(13.3 \%)$ & 0.54 & $0.37-0.78$ & & 0.51 & $0.34-0.76$ & \\
\hline Constant & - & - & 0.21 & $0.17-0.25$ & $<0.001$ & - & - & - \\
\hline \multicolumn{9}{|l|}{ Able to read newspaper or letter } \\
\hline No & $866(72.8 \%)$ & $323(27.2 \%)$ & - & - & $<0.001$ & - & - & - \\
\hline Yes & $4972(83.5 \%)$ & $985(16.5 \%)$ & 0.50 & $0.42-0.59$ & & - & - & - \\
\hline Constant & - & - & 0.28 & $0.23-0.35$ & $<0.001$ & - & - & - \\
\hline \multicolumn{9}{|l|}{ Religion } \\
\hline Apostolic & 2005 (81.8\%) & $445(18.2 \%)$ & - & - & 0.245 & - & - & - \\
\hline Other Christian denomination & $1863(83.1 \%)$ & $380(16.9 \%)$ & 0.99 & $0.83-1.19$ & & - & - & - \\
\hline Other, including no religion & $1970(80.3 \%)$ & $483(19.7 \%)$ & 1.14 & $0.95-1.35$ & & - & - & - \\
\hline Constant & - & - & 0.15 & $0.12-0.19$ & $<0.001$ & - & - & - \\
\hline \multicolumn{9}{|l|}{ Tribe } \\
\hline Shona & 4142 (83.7\%) & $807(16.3 \%)$ & - & - & $<0.001$ & - & - & 0.0060 \\
\hline Ndebele & $925(78.5 \%)$ & $254(21.5 \%)$ & 1.43 & $1.14-1.79$ & & 1.28 & $1.02-1.61$ & \\
\hline Kalanga & $489(75.2 \%)$ & $161(24.8 \%)$ & 1.76 & $1.36-2.29$ & & 1.58 & $1.21-2.07$ & \\
\hline Tonga & $23(82.1 \%)$ & $5(17.9 \%)$ & 1.21 & $0.39-3.70$ & & 0.93 & $0.29-3.03$ & \\
\hline Other & $250(76.5 \%)$ & $77(23.5 \%)$ & 1.66 & $1.20-2.31$ & & 1.47 & $1.04-2.07$ & \\
\hline I don't wish to answer & $9(69.2 \%)$ & $4(30.8 \%)$ & 2.70 & $0.67-10.94$ & & 2.56 & $0.61-10.73$ & \\
\hline Constant & - & - & 0.14 & $0.12-0.17$ & $<0.001$ & - & - & - \\
\hline \multicolumn{9}{|l|}{ Occupation } \\
\hline Student & $531(75.9 \%)$ & $168(24.1 \%)$ & - & - & $<0.001$ & - & - & \\
\hline Subsistence farmer & $3836(83.1 \%)$ & 784 (16.9\%) & 0.57 & $0.46-0.72$ & & 0.83 & $0.62-1.10$ & \\
\hline Self-employed & 1045 (80.2\%) & $258(19.8 \%)$ & 0.70 & $0.54-0.92$ & & 1.08 & $0.79-1.46$ & 0.0131 \\
\hline Formal employment & $426(81.3 \%)$ & $98(18.7 \%)$ & 0.68 & $0.49-0.95$ & & 1.17 & $0.81-1.70$ & \\
\hline Constant & - & - & 0.25 & $0.19-0.32$ & $<0.001$ & - & - & - \\
\hline
\end{tabular}


Table 1 (continued)

\begin{tabular}{|c|c|c|c|c|c|c|c|c|}
\hline Individual characteristics & $\begin{array}{l}\text { Ever heard of HIVST } \\
\mathrm{N}=5838 \text { (Row \%) }\end{array}$ & $\begin{array}{l}\text { Never heard of } \\
\text { HIVST N=1308 (Row } \\
\% \text { ) }\end{array}$ & $\mathrm{OR}^{*}$ & $95 \% \mathrm{Cl}$ & P-value & $\mathrm{aOR}^{\$}$ & $95 \% \mathrm{Cl}$ & P-value \\
\hline \multicolumn{9}{|l|}{ Regular salary } \\
\hline No & 4909 (81.9\%) & $1084(18.1 \%)$ & - & - & \multirow[t]{2}{*}{0.327} & - & - & - \\
\hline Yes & $929(80.6 \%)$ & $224(19.4 \%)$ & 1.10 & $0.91-1.33$ & & - & - & - \\
\hline Constant & - & - & 0.16 & $0.13-0.19$ & $<0.001$ & - & - & - \\
\hline \multicolumn{9}{|l|}{ Perception general health } \\
\hline Very good & $1534(82.8 \%)$ & $318(17.2 \%)$ & - & - & \multirow[t]{5}{*}{0.027} & - & - & \multirow[t]{5}{*}{0.0165} \\
\hline Good & $2247(82.8 \%)$ & $466(17.2 \%)$ & 0.96 & $0.80-1.15$ & & 1.04 & $0.85-1.25$ & \\
\hline Fair & $1184(80.9 \%)$ & $278(19.1 \%)$ & 1.02 & $0.83-1.26$ & & 1.10 & $0.88-1.38$ & \\
\hline Poor & $797(78.8 \%)$ & $214(21.2 \%)$ & 1.20 & $0.96-1.51$ & & 1.30 & $1.01-1.67$ & \\
\hline Don't want to answer & $76(70.4 \%)$ & $32(29.6 \%)$ & 1.93 & $1.16-3.22$ & & 2.15 & $1.27-3.65$ & \\
\hline Constant & - & - & 0.16 & $0.13-0.19$ & $<0.001$ & - & - & - \\
\hline \multicolumn{9}{|l|}{ Living here last 12 months } \\
\hline No & $292(70.7 \%)$ & $121(29.3 \%)$ & - & - & \multirow[t]{2}{*}{$<0.001$} & - & - & \multirow[t]{2}{*}{$<0.001$} \\
\hline Yes & $5546(82.4 \%)$ & $1187(17.6 \%)$ & 0.44 & $0.33-0.57$ & & 0.48 & $0.36-0.63$ & \\
\hline Constant & - & - & 0.34 & $0.25-0.46$ & $<0.001$ & - & - & - \\
\hline \multicolumn{9}{|l|}{$S S Q \geq 9$} \\
\hline No & $490(60.4 \%)$ & $732(39.6 \%)$ & - & - & \multirow[t]{2}{*}{0.262} & - & - & - \\
\hline Yes & $5348(84.4 \%)$ & $576(15.6 \%)$ & 0.92 & $0.80-1.06$ & & - & - & - \\
\hline Constant & - & - & 0.16 & $0.14-0.20$ & $<0.001$ & - & - & - \\
\hline \multicolumn{9}{|l|}{ Ever tested for HIV } \\
\hline No & $3193(81.3 \%)$ & $321(18.7 \%)$ & - & - & \multirow[t]{2}{*}{$<0.001$} & - & - & \multirow[t]{2}{*}{$<0.001$} \\
\hline Yes & $2645(82.1 \%)$ & $987(17.9 \%)$ & 0.24 & $0.20-0.30$ & & 0.30 & $0.25-0.37$ & \\
\hline Constant & - & - & 0.55 & $0.44-0.69$ & $<0.001$ & - & - & - \\
\hline \multicolumn{9}{|l|}{ Household head } \\
\hline Household head & $2398(83.2 \%)$ & $485(16.8 \%)$ & - & - & \multirow[t]{3}{*}{0.0008} & - & - & \multirow[t]{3}{*}{0.1002} \\
\hline Household head representative & $777(83.6 \%)$ & $153(16.4 \%)$ & 0.93 & $0.74-1.17$ & & 1.07 & $0.83-1.37$ & \\
\hline Not head/represent & $2663(79.9 \%)$ & $670(20.1 \%)$ & 1.27 & $1.10-1.47$ & & 1.21 & $1.01-1.45$ & \\
\hline Constant & - & - & 0.14 & $0.12-0.18$ & $<0.001$ & - & - & - \\
\hline Constant multivariable model & - & - & - & - & - & 1.30 & $0.84-2.03$ & 0.245 \\
\hline
\end{tabular}

*OR: odds ratio, bivariable analysis, adjusted for clustering on community and household level, people having heard of HIVST as reference group; $\$=$ aOR: adjusted odds ratio, multivariable mixed-effect logistic regression, adjusted for clustering on community and household level after backward reduction, people having heard of HIVST as reference group; $\mu=$ Ordinary (O) Level-basic level of the General Certificate of Education completed in the third/fourth years secondary school, a subject-based qualification; $£=$ Advanced (A) Level-advanced level of the General Certificate of Education completed in the fifth/sixth years of secondary school, a subject-based qualification

Possible explanations may be linked to general trends in HIV testing. Younger people and those less educated are less knowledgeable about HIV, and thus may know less about different HIV testing options, including self-testing $[24,25]$. Despite the high HIVST awareness achieved by our community-based distribution model, culminating in high testing rates among individuals who might not otherwise test (i.e., men, young people, those testing for the first time), some still remained unaware of their HIV status [26-29]. Complementing community-based distribution with other HIVST distribution models such as those through health facilities and youth clinics, by sexual partners or secondary distribution and workplace programmes will be needed to reach those remaining unaware [30-36].

Non-household heads were more likely to not have heard of HIVST. As was reported in qualitative studies that were done alongside this research (data not reported here), this may be because when distributors approach households, they are culturally expected to first approach the head of household, who may not invite the rest of the household to the discussion [37]. Future efforts should ensure that everyone in a household is invited to discussions, with platforms created for separate discussions as appropriate (e.g., young people would like HIVST discussions to be held separately from their parents/guardians) 
[37]. A community-based program on HIVST in rural Malawi found that HIVST was more prevalent among individuals who shared a household with someone who reported HIVST [29]. Understanding the role of household dynamics on facilitating community-based distribution activities within the household should be further investigated. Alongside, alternative distribution methods should be implemented for those who are uncomfortable accepting and performing an HIV self-test in the presence of other household members, for example, through youth centres or peer to peer distribution for young people [37-41] Furthermore, appropriate promotion tools such as mobile platforms and social media technology should be used to increase HIVST awareness among young people [39].

The population-based survey outcomes were based on self-reporting, which may have been subject to social desirability bias. To minimize this bias, ACASI was used [42]. Despite this, this study provides new insights into characteristics of individuals who remain unaware of HIVST following community-based HIVST kit distribution and confirms the presence of ongoing barriers to HIV testing. Lastly, our results are specific for community-based door-to-door distribution of HIVST kits. Other distribution models or a different intervention design might have affected awareness of HIVST differently.

\section{Conclusions}

Around one fifth of survey participants remain unaware of HIVST even after an intensive community-based doorto-door HIVST distribution. Of note, those least likely to have heard of self-testing were younger, less educated and less likely to have tested previously. Household heads appear to play an important role in granting or denying access to self-testing to other household members during door-to-door distribution. Differentiated distribution models are needed to ensure access to all.

\section{Abbreviations \\ ACASI: Audio computer assisted self interview; ART: Antiretroviral therapy; DHS: Demographic and health survey; EA: Enumeration area; HIV: Human immunodeficiency virus; HIVST: HIV self-testing; SSQ: Shona Symptom Ques- tionnaire; STAR: Self-Test Africa.}

\section{Supplementary Information}

The online version contains supplementary material available at https://doi. org/10.1186/s12879-022-07027-9.

Additional file 1. Household questionnaire Zimbabwe.

\section{Acknowledgements}

STAR Initiative collaborators include Population Services International, Society for Family Health, the London School of Hygiene and Tropical Medicine,
University College London, the Liverpool School of Tropical Medicine, the World Health Organization, CeSHHAR, Zambart and the Malawi-LiverpoolWellcome Trust Clinical Research Unit.

\section{About this supplement}

This article has been published as part of BMC Infectious Diseases Volume 22 Supplement 1 2021: Innovating with HIV self-testing for impact in southern Africa: Lessons learned from the STAR (Self-Testing AfRica) Initiative. The full contents of the supplement are available at https://bmcinfectdis.biomedcent ral.com/articles/supplements/volume-22-supplement-1.

\section{Authors' contributions}

AR, ES, FC conceptualized the paper. AR conducted the analysis and wrote the first draft. KH, CJ, EC, MN, FC and ES contributed to revisions of the manuscript, and all authors have reviewed the final manuscript. All authors read and approved the final manuscript.

\section{Funding}

The STAR Initiative is funded by UNITAID (PO\# 10140-0-600 and PO\# 8477-0-600).

\section{Availability of data and materials}

The datasets used and/or analysed during the current study are available from the corresponding author on reasonable request.

\section{Declarations}

\section{Ethics approval and consent to participate}

Ethical approval was obtained from Medical Research Council of Zimbabwe (MRCZ/A/2038), University College London Ethics Committee (6084/004) and London School of Hygiene and Tropical. Medicine Ethics Committee (11738). Before filling in the questionnaire, participants were informed about the study, the procedures and the voluntary nature of study participation. Participants provided written consent to participate.

\section{Consent for publication}

Not applicable.

\section{Competing interests}

The authors have no competing interests.

\section{Author details}

'Department of Public Health, Institute of Tropical Medicine, Nationalestraat 155, 2000 Antwerp, Belgium. ${ }^{2}$ Centre for Sexual Health and HIV AIDS Research (CeSHHAR), Harare, Zimbabwe. ${ }^{3}$ Liverpool School of Tropical Medicine, Liverpool, UK. ${ }^{4}$ Population Services International, Cape Town, South Africa. ${ }^{5} \mathrm{Global}$ HIV, Hepatitis and STI Programmes, World Health Organization, Geneva, Switzerland. ${ }^{6}$ Department of Clinical Research and Infection Disease, London School of Hygiene and Tropical Medicine, London, UK. ${ }^{7}$ Faculty of Epidemiology and Population Health, London School of Hygiene and Tropical Medicine, London, UK.

Received: 23 December 2021 Accepted: 3 January 2022

Published: 13 January 2022

References

1. "Global HIV \& AIDS statistics - 2020 fact sheet | UNAIDS." [Online]. Available: https://www.unaids.org/en/resources/fact-sheet. [Accessed: 01-Apr-2021].

2. Wong V, Johnson C, Cowan E. HIV self-testing in resource-limited settings: regulatory and policy considerations. AIDS behav. 2014;18:415-21.

3. UNAIDS. Understanding fast-track accelerating action to end the AIDS epidemic by 2030. 2015.

4. Figueroa C, Johnson C, Verster A, Baggaley R. Attitudes and acceptability on HIV self-testing among key populations: a literature review. AIDS Behav. 2015;19:1949-65. 
5. Johnson CC, et al. Review article Examining the effects of HIV self-testing compared to standard HIV testing services: a systematic review and meta-analysis. J Int AIDS Soc. 2017;20:1-10.

6. Harichund C, Moshabela M. Acceptability of HIV Self-testing in subSaharan Africa: scoping study. AIDS behav. 2018;22(2):560-8.

7. Krause J, Subklew-sehume F, Kenyon C, Colebunders R. Acceptability of HIV self-testing: a systematic literature review. BMC Public Health. 2013;13:9.

8. Stevens DR, Vrana CJ, Dlin RE, Korte JE. A global review of HIV self-testing: themes and implications. AIDS behav. 2018;22(2):497-512.

9. Figueroa C, et al. Reliability of HIV rapid diagnostic tests for self-testing compared with testing by health-care workers: a systematic review and meta-analysis. Lancet HIV. 2018;5:277-90.

10. WHO. HIV self-testing and partner notification supplement to consolidated guidelines on HIV testing services. 2016; (December).

11. P.WHO Brief. Who recommends Hiv self-testing-evidence update and considerations for success policy brief. 2019; (November): 1-4.

12. Indravudh PP et al. Effect of community-led delivery of HIV self-testing on HIV testing and antiretroviral therapy initiation in Malawi: a clusterrandomised trial. PLoS Med. 2021; 18(5)

13. Hensen B et al. Who Accepts and Who Uses Community-Based Secondary Distribution HIV Self-Testing (HIVST) Kits? Findings From the Intervention Arm of a Cluster-Randomized Trial of HIVST Distribution Nested in Four HPTN 071 (PopART) Communities in Zambia. 2020.

14. Matovu JKB, et al. Feasibility and acceptability of a pilot, peer-led HIV self-testing intervention in a hyperendemic fishing community in rural Uganda. PLoS ONE. 2020;15(8):e236141.

15. Hatzold K, et al. HIV self-testing: breaking the barriers to uptake of testing among men and adolescents in sub-Saharan Africa, experiences from STAR demonstration projects in Malawi, Zambia and Zimbabwe. J Int AIDS Soc. 2019:22(S1):43-52.

16. Sibanda EL, et al. Community-based HIV self-testing: a clusterrandomised trial of supply-side financial incentives and time-trend analysis of linkage to antiretroviral therapy in Zimbabwe. BMJ Glob Heal. 2021;6(Suppl 4):e003866.

17. Patel V, Simunyu E, Gwanzura F, Lewis G, Mann A. The Shona Symptom Questionnaire: the development of an indigenous measure of common mental disorders in Harare. Acta Psychiatr Scand. 1997;95(6):469-75.

18. Moore GF, et al. Process evaluation of complex interventions: medical research council guidance. BMJ. 2015;350:1-7.

19. Mavengere Y, Sibanda EL, Hatzold K, Cowan F, Mugurungi O, Mavedzenge S. Can 'late-read' of self-test devices be used as a quality assurance measure? Results of a pilot HIV self-test project in Zimbabwe. 2016;541.

20. Johnson C, et al. Use and awareness of and willingness to self-test for HIV: an analysis of cross-sectional population-based surveys in Malawi and Zimbabwe. BMC Public Health. 2020;20(1):1-13.

21. Takarinda KC, et al. Factors associated with ever being HIV-tested in Zimbabwe: an extended analysis of the Zimbabwe Demographic and Health Survey (2010-2011). PLoS ONE. 2016;11(1):1-18.

22. Peltzer K, Matseke G, Mzolo T, Majaja M. Determinants of knowledge of HIV status in South Africa: results from a population-based HIV survey. BMC Public Health. 2009; 9(174).

23. Giguère $\mathrm{K}$ et al. Trends in knowledge of HIV status and efficiency of HIV testing services in Sub-Saharan Africa (2000-2020): a modelling study of survey and HIV testing program data. medRxiv. 2020; 3018(20).

24. Gazimbi MM, Magadi MA. A Multilevel analysis of the determinants of HIV testing in Zimbabwe: evidence from the demographic and health surveys. HIV/AIDS Res Treat Open J. 2017;4(1):14-31.

25. Joint United Nations Programme on HIV/AIDS, "Young people and HIV/ aids opportunity in crisis."

26. UNAIDS, "Miles to go: closing gaps breaking barriers righting injustices," 2018

27. "Young people and men less likely to know their HIV status | UNAIDS." [Online]. Available: https://www.unaids.org/en/resources/presscentre/ featurestories/2019/december/young-people-and-men-less-likely-toknow-their-hiv-status. [Accessed: 16-Apr-2020].

28. Sibanda E, Neuman M, Tumushime M, Hatzold K. Linkage to care after HIV self-testing in Zimbabwe: a cluster-randomised trial. in CROI 2018, 2018.

29. Indravudh PP, et al. Who is reached by HIV self-testing? Individual factors associated with self-testing within a community-based program in Rural Malawi. JAIDS J Acquir Immune Defic Syndr. 2020;85(2):165-73.
30. Kelvin EA, et al. Offering self-administered oral HIV testing to truck drivers in Kenya to increase testing: a randomized controlled trial. AIDS Care Psychol Socio-Med Asp AIDS/HIV. 2018;30(1):47-55.

31. Lippman S, Lane T, Rabede O, Gilmore H, Chen Y-H, Mlotshwa N. High acceptability and increased HIV testing frequency following introduction of HIV self-testing and network distribution among South African MSM. J Acquir Immune Defic Syndr. 2018;77(3):279-87.

32. Tun W, et al. Uptake of HIV self-testing and linkage to treatment among men who have sex with men (MSM) in Nigeria: a pilot programme using key opinion leaders to reach MSM. J Int AIDS Soc. 2018;21(S5):e25124.

33. Smith P, Wallace M, Bekker LG. Adolescents' experience of a rapid HIV self-testing device in youth-friendly clinic settings in Cape Town South Africa: a cross-sectional community based usability study. J Int AIDS Soc. 2016;19(21111):1-6.

34. Hector J, et al. Acceptability and performance of a directly assisted oral HIV self-testing intervention in adolescents in rural Mozambique. PLoS ONE. 2018;13(4):e0195391.

35. Dovel K, et al. Effect of facility-based HIV self-testing on uptake of testing among outpatients in Malawi: a cluster-randomised trial. Lancet Glob Heal. 2020;8(2):e276-87.

36. WHO, "HIV SELF-TESTING AT THE WORKPLACE," 2018.

37. Indravudh PP, et al. 'I will choose when to test, where I want to test': investigating young people's preferences for HIV self-testing in Malawi and Zimbabwe. AIDS. 2017;31(February):S203-12.

38. Obiezu-Umeh C et al. Young people's preferences for HIV self-testing services in Nigeria: a qualitative analysis. BMC Public Health. 2021; 21(1)

39. Iwelunmor J, et al. The 4 youth by youth HIV self-testing crowdsourcing contest: a qualitative evaluation. PLOS ONE. 2020;15(5):e0233698.

40. Bwalya C, et al. Social response to the delivery of HIV self-testing in households: experiences from four Zambian HPTN 071 (PopART) urban communities. AIDS Res Ther. 2020;17(1):32.

41. Shahmanesh M et al. Effect of Peer-distributed HIV self-test kits on demand for biomedical HIV prevention in rural KwaZulu-Natal, South Africa: a three-armed cluster-randomised trial comparing social-networks versus direct delivery. BMJ Glob Heal. 2020

42. Langhaug $L F$, et al. How you ask really matters: randomised comparison of four sexual behaviour questionnaire delivery modes in Zimbabwean youth. Sex Transm Infect. 2011;87(2):165-73.

\section{Publisher's Note}

Springer Nature remains neutral with regard to jurisdictional claims in published maps and institutional affiliations.

Ready to submit your research? Choose BMC and benefit from

- fast, convenient online submission

- thorough peer review by experienced researchers in your field

- rapid publication on acceptance

- support for research data, including large and complex data types

- gold Open Access which fosters wider collaboration and increased citations

- maximum visibility for your research: over 100M website views per year

At BMC, research is always in progress.

Learn more biomedcentral.com/submissions 